$\Phi=$

\title{
Clinical presentation and management of mycetoma in gezira mycetoma center in Sudan
}

\author{
Moiez M. Aboudi Ahmed ${ }^{1}$, Ahmad Alamin Alshiekh ${ }^{2}$, Mohammed D. Awadalla Gismalla ${ }^{2 *}$, Awad Ali M. Alawad ${ }^{3}$ \\ ${ }^{1}$ General Surgeon, Sudan medical specialization Board, Khartoum, Sudan \\ ${ }^{2}$ Department of Surgery, University of Gezira, Medani, Sudan \\ ${ }^{3}$ Department of surgery, Prince Sultan Hospital, Medina, KSA \\ *Corresponding author E-mail: mohadaff22@gmail.com
}

\begin{abstract}
Background: Mycetoma is a neglected tropical disease characterised by deformity and disabilities with various medical, health, and socioeconomic impacts on the affected communities. It is a common health problem in Gezira state in Sudan.

Objective: This study was conducted to review the clinical presentation and management of mycetoma in Gezira Mycetoma Center in Medani, Sudan.

Methodology: This was a prospective descriptive health facility-based study conducted among 100 patients diagnosed with mycetoma attended to Gezira Mycetoma Center during the period from October 2014 to Sept. 2015. Variable checked was demographic characteristic, clinical presentation, types of mycetoma, and types of surgery done.

Results: The commonest age was $20-40$ years, which represents $49(49 \%)$. Males were $76(76 \%)$. Participants were mostly farmers or animal breeders with percentage of $31 \%$ and $12 \%$ respectively. All patients presented with a swelling (100\%) and mostly with discharge in a sinuses $(75 \%)$. The vast majority of patients reside in Gezira State (82\%). Eumycetoma was reported in $98 \%$ of cases versus $2 \%$ actinomycetoma. Diagnosis depended on clinical examination mainly and X-ray for bone involvement which was reported in $15 \%$. All cases underwent surgical intervention in the form of wide local excision (81\%), amputation (17\%) and debulking (2\%).

Conclusion: The study concluded that most of the patients presented late, with history of inadequate management.
\end{abstract}

Keywords: Mycetoma; Recurrence; Amputation.

\section{Introduction}

Mycetoma is a unique neglected tropical disease. Mycetoma is a chronic subcutaneous granulomatous lesion caused either by true fungi (eumycetoma ) or by higher bacteria, mainly aerobic actinomycetes (actinomycetoma) (Zijlstra et al. 2016). It was first described by Gill of Madura in south India in 1842, hence the name 'madura foot'. In 1860 Carter introduced the term mycetoma ('fungal tumor') to indicate the origin of the disease (van de Sande 2013).

Mycetoma has a world-wide distribution but this is extremely uneven. It is endemic in many tropical and subtropical regions. It prevails in the mycetoma belt that stretches in a band between the latitudes of 150 South and 300 North (Fahal \& Sabaa 2010). The belt includes Sudan, Somalia, Senegal, India, Yemen, Mexico, Venezuela, Columbia, Argentina and others. The mycetoma belt encases an area of forest trees and savannah, the dominant plants being various species of Acacia in addition to a variety of other thorny trees. The geographical distribution of mycetoma and its individual causative organisms shows considerable geographical variations, which can be convincingly explained on an environmental basis. The current study aimed to review the clinical presentation and management of mycetoma among 100 patients attended to Gezira mycetoma center.

\section{Material and methods}

This was a prospective descriptive health facility-based study conducted among 100 patients diagnosed with mycetoma attended to Gezira Mycetoma Center during the period from October 2014 to Sept. 2015. Sample size was determined by total coverage method to include all patients attended during the study period and they were 107 patients, the response rate was $100 \%$, but after excluding cases with missed data the final sample size was 100 participants.

Statistical analysis was performed via SPSS software (SPSS, Chicago, IL, USA). Continuous variables were compared using student's t test (for paired data) or Mann-Whitney U test for nonparametric data. For categorical data, comparison was done using Chi-square test (X2) or Fisher's Exact test when appropriate. A P value of $<0.05$ was considered statistically significant.

Ethical clearance and approval for conducting this research was obtained from the general manager of the center and informed written consent was obtained from every respondent who agreed to participate in the study. The potential participants were clearly assured that their participation in this study was voluntary and that they could withdraw at any stage and that any data obtained would be treated confidentially and would be used for the purpose of the research only. 


\section{Results}

The commonest age was 20-40 years, which represents 49(49\%). Males were $76(76 \%)$. Participants were mostly farmers or animal breeders with percentage of $31 \%$ and $12 \%$ respectively. The Demographic characteristics of patients showed in Table (1). It showed age distribution, male: female ratio, residence and occupations of patients. All patients in the study complained of swelling (100\%), among whom $39(39 \%)$ reported duration of more than one year, 32(32\%) complained for less than 6 months and 29(29\%) complained for 6-12 years. Most of the patients (75\%) presented with discharge in a sinuses. The vast majority of patients reside in Gezira State (82\%). A history of previous operation (recurrence) was reported positively in 39(39\%) of patients. Eumycetoma was reported in $98 \%$ of cases versus $2 \%$ actinomycetoma. Diagnosis was depended on clinical examination mainly and radiography for bone involvement which was reported in $15 \%$. All cases underwent surgical intervention in the form of wide local excision (81\%), amputation (17\%) and debulking (2\%). The heath personnel who did the previous operations and the health facilities were operation done were shown in Table 2. Table 3 Showed that the classifying operations done for mycetoma patients.

Table .1: Shows the Demographic Characteristics of Participants $(\mathrm{N}=100)$

\begin{tabular}{lll}
\hline Demographic characteristics & Frequency & Percentage \\
\hline Age distribution & & \\
$<20$ & 29 & 29.0 \\
$20-40$ & 49 & 49.0 \\
$>40$ & 22 & 22.0 \\
Sex & & \\
Male & 76 & 76.0 \\
Female & 24 & 24.0 \\
Residence State & & \\
Elgazira & 82 & 82.0 \\
Senar & 7 & 7.0 \\
Elgadarif & 4 & 4.0 \\
Kasala & 2 & 2.0 \\
others & 5 & 5.0 \\
Occupation & & \\
farmer & 31 & 31.0 \\
animals breeder & 12 & 12.0 \\
House Wife & 16 & 16.0 \\
Student & 26 & 26.0 \\
Others & 15 & 15.0 \\
\hline
\end{tabular}

Table .2: Shows Details about the Place Where Surgery Done and the Operator

Where operation done

\begin{tabular}{lll}
\hline Health Center & 7 & $18 \%$ \\
Rural Hospital & 30 & $76.9 \%$ \\
Teaching Hospital & 2 & $5.1 \%$ \\
Total & 39 & $100 \%$ \\
Who did operation & & \\
Specialist & 2 & $5.1 \%$ \\
General Practitioner & 28 & $71.8 \%$ \\
Medical assistant & 6 & $15.4 \%$ \\
Nurse & 3 & $7.7 \%$ \\
Total & 39 & $100 \%$ \\
\hline
\end{tabular}

\begin{tabular}{lll}
\hline & \multicolumn{2}{c}{ Table .3: Shows Type of Surgery } \\
\hline Operation & Frequency & Percentage \\
\hline WLE & 71 & 71.0 \\
WLE+ Skin graft & 10 & 10.0 \\
Amputation & 17 & 17.0 \\
Debulking & 2 & 2.0 \\
Total & 100 & 100.0 \\
\hline
\end{tabular}


1996). Also, literature review showed the predomination of actinomyces reporting that, Infection can be caused by true fungi in $40 \%$ cases where it is known as eumycetoma and by filamentous bacteria of order actinomycetes (actinomycetoma) in 60\% cases (Boiron et al. 1998).

All patients, except one received pre-operative medical treatment (99\%), in form of antifungal, antibiotics and folic acid. All patients in the current study were treated surgically, out of them $81 \%$ underwent wild local excision (WLE), and only $10 \%$ who were applied skin graft due to total excision and small in size. Other operations included are amputation which was done for $17 \%$, and debulking (2\%). It was reported that, eumycetoma is well encapsulated and great care must be exercised not to rupture the capsule, which may lead to recurrence by transferring the fungal element into other parts of the operative field (Suleiman et al. 2016). Actinomycetoma has an ill-defined border; therefore a margin of healthy tissue should always be excised with the lesion.

\section{Conclusion}

The study concluded that most of the patients presented late, with history of inadequate management. We suggest that the attitude of patients towards mycetoma has to change through continuous but targeted public education.

\section{References}

[1] Ahmed SA, Abbas MA, Jouvion G, Al-Hatmi AM, de Hoog GS, Kolecka A \& Mahgoub el S (2015): Seventeen years of subcutaneous infection by Aspergillus flavus; eumycetoma confirmed by immunohistochemistry. $\quad$ Mycoses $\quad 58, \quad 728-734$ https://doi.org/10.1111/myc.12422.

[2] Boiron P, Locci R, Goodfellow M, Gumaa SA, Isik K, Kim B, McNeil MM, Salinas-Carmona MC \& Shojaei H (1998): Nocardia, nocardiosis and mycetoma. Med Mycol 36 Suppl 1, 26-37.

[3] Fahal A, Mahgoub el S, El Hassan AM \& Abdel-Rahman ME (2015): Mycetoma in the Sudan: an update from the Mycetoma Research Centre, University of Khartoum, Sudan. PLoS Negl Trop Dis 9, e0003679. https://doi.org/10.1371/journal.pntd.0003679.

[4] Fahal A, Mahgoub el S, El Hassan AM, Abdel-Rahman ME, Alshambaty Y, Hashim A, Hago A \& Zijlstra EE (2014a): A new model for management of mycetoma in the Sudan. PLoS Negl Trop Dis 8, e3271.

[5] Fahal AH (2004): Mycetoma: a thorn in the flesh. Trans $R$ Soc Trop Med Hyg 98, 3-11. https://doi.org/10.1016/S0035-9203(03)00009-9.

[6] Fahal AH \& Sabaa AH (2010): Mycetoma in children in Sudan. Trans $R$ Soc Trop Med Hyg 104, 117-121. https://doi.org/10.1016/j.trstmh.2009.07.016.

[7] Fahal AH, Shaheen S \& Jones DH (2014b): The orthopaedic aspects of mycetoma. Bone Joint J 96-B, 420-425.

[8] Hay RJ \& Fahal AH (2015): Mycetoma: an old and still neglected tropical disease. Trans $R$ Soc Trop Med Hyg 109, 169-170. https://doi.org/10.1093/trstmh/trv003.

[9] IA ELH, Fahal AH \& Gasim ET (1996): Fine needle aspiration cytology of mycetoma. Acta Cytol 40, 461-464. https://doi.org/10.1159/000333899.

[10] Suleiman SH, Wadaella el S \& Fahal AH (2016): The Surgical Treatment of Mycetoma. PLoS Negl Trop Dis 10, e0004690. https://doi.org/10.1371/journal.pntd.0004690.

[11] Van de Sande WW (2013): Global burden of human mycetoma: a systematic review and meta-analysis. PLoS Negl Trop Dis 7, e2550. https://doi.org/10.1371/journal.pntd.0002550.

[12] Zijlstra EE, van de Sande WW \& Fahal AH (2016): Mycetoma: A Long Journey from Neglect. PLoS Negl Trop Dis 10, e0004244. https://doi.org/10.1371/journal.pntd.0004244. 